\title{
Digital Segregation: Gender, Occupation, and Access to Politics
}

\author{
Amanda Friesen \\ Indiana University-Purdue University Indianapolis \\ Ryan Burge \\ Eastern Illinois University \\ Kylee Britzman \\ Lewis-Clark State College
}

\begin{abstract}
In the United States, women often show less interest in politics, and under some conditions, perform worse than men on political knowledge tests. In an age where education levels have reached parity, we suggest one of the explanations for gender differences in political engagement might be due to selection of occupation. Past research has shown women and men segregate into different occupations due to early gender socialization, differences in interest, and structural barriers. It is possible that due to these segregation effects, women in traditional female occupations (e.g. education, health care, service work) may have less access to personal internet use and news sources during their work days. Using the 2014 General Social Survey, we create a new occupational typology based on access to the internet to explore whether individuals in certain sectors differ in their political engagement and how these occupations are also divided by gender, race and class. Then we apply the technology use measure to the 2016 American National Election Study and find that technology access on the job does not seem to be related to political knowledge, once we account for education, which offers some insight into the mechanisms by which individuals gain this knowledge. In addition, the interaction between total media consumption and tech use suggests that the gap in political knowledge between men and women is stubbornly persistent.
\end{abstract}

Keywords: gender, occupation, political knowledge, technology use

Forthcoming in Social Science Computer Review

https://doi.org/10.1177/0894439319851164 
Full-time working Americans spend a lot of time at their place of employment. For many people, work offers opportunities for socialization. There is speculation and some measure of the veritable water cooler by which workers chat, learn, and network with their peers, bosses, and subordinates. In some instances, workplace discussions are politically oriented and offer workers a chance to hear a diverse range of political perspectives (Mutz \& Mondak, 2006). Yet, for most social science research, the workplace and associated occupation serve as a code, a socio-economic measure, or a secondary/third/fourth identity to what we assume happens in other parts of life. By not fully exploring how people engage with others at work, we are potentially missing a major contributor of people's political behaviors. We generally understand how workplace socialization influences political discussions and exposure to different views. Yet, we know much less about how online social networking and reading political content at work influence political behavior variables like political knowledge. Thus, in this paper we assess how differential access to technology at work, based on gender segregation into particular careers, influences political knowledge.

People's workplaces are a place to build careers by networking with coworkers, bosses, and subordinates. Yet for some Americans, the workplace also serves as an extension of their personal lives. They are friends with co-workers (Sias \& Cahill, 1998) and socialize with them both in and out of the workplace (Tse, Dasborough, \& Ashkanasy, 2008). Additionally, they can interact with friends outside of the workplace by taking personal phone calls, checking email, browsing Facebook or Instagram, and catching up on the latest news from time to time or at least over the lunch hour. However, for others, the time at work may feel like a cave away from the outside world - one from which people emerge to find an event of great significance has taken place -- a friend had a baby, or a president has made another social media declaration. Access to technology at work, whether via email, perusing news websites, or through social media, serves as one way to acquire political information while on the job. Additionally, some research suggests that many workers are using 
social media in particular to access political information at much higher rates than even a few years ago. For instance, since the 2016 presidential election, workers have reported spending an average of two hours per day reading social media posts at work and about $20 \%$ say they read 20 or more political social media posts at work every day (McGregor, 2017).

As social scientists, we rarely account for when and where these forms of digital communication occur. This leads us to ask are there differences between those that remain connected at work, at home, and at play versus those that have limited or no access to the internet for up to eight hours a day? We also know that occupations are segregated by demographic characteristics - thus, could these differences help explain why we find persistent gaps that exist in political knowledge across gender?

Certainly, occupational prestige and "choice" could represent a proxy for class status, income, education, and certain types of identity. But what if the very nature of particular jobs precludes workers from engaging in outside matters during working hours? Individuals may seek careers in education, social work, or health care as a way to "make a difference," yet these very same sectors may disallow personal political engagement on the job. School teachers often joke about scheduling in bathroom breaks, and there are often strict rules about using computers for personal purposes. Add to this effect that women tend to occupy these roles, and the moment they leave work, they start their "second shift" as wives and mothers, and who has time to check Twitter? Read CNN? Follow the links someone posted to Facebook? In the words of a teacher with small children, “maybe women just don't have the time or energy to worry about politics."

So, what's going on with occupation? Social scientists and government offices measure it, extensively. It's coded pedantically, but we do not know how these differences in occupations influence political engagement at the workplace. We attempt to address this gap in political information access by first using the 2014 General Social Survey to define the extent to which 
occupational groups have access to the internet or technology at work and how this breaks down by gender. We then apply the technology use measure to the 2016 American National Election Study to test whether access at work is associated with varying levels of political knowledge.

\section{Occupational Selection and Segregation}

Self-selection into certain occupations and subsequent gender segregation into particular careers likely begins early in life for men and women. From an early age, boys and girls learn how to behave according to their ascribed gender roles, usually because those around them tend to classify sex before engaging with them (Ridgeway, 2009). Similarly, sex segregation can emerge quite early in the path to many careers (Correll, 2001). While it may appear that men and women are making their own choices when it comes to occupation, they may be involuntarily led into specific careers because of their socialization as children (Ridgeway, 2009). Adolescents develop interests that influence the classes taken in high school, which in turn may influence whether and what is pursued in higher education, eventually leading to occupation choice. Sex differences persistently emerge in the reasoning for why women and men choose their specific occupations (Su, Round, \& Armstrong, 2009). For example, women often show interests in social and artistic activities, and men may be drawn to or encouraged to pursue scientific, technical, and mechanical activities (Su et al., 2009). Since women tend to enjoy working with people more than things (Su et al., 2009), they may pursue majors/fields of study that match those interests (Correll, 2001).

In the past several decades, however, women have started transitioning into certain maledominated occupations. This shift is not necessarily related to a change in female curiosities as evidence still shows that men and women continue to have different educational and occupational interests (Su et al., 2009), but instead from women attempting to bypass the "glass ceiling" set in female-dominated industries. In order for women to continue up the ladder of mobility, many of them have to either make a career change or go back to school. A nurse cannot be promoted to a 
doctor, an elementary school teacher cannot work her way up to superintendent, and a social worker cannot become a supervisor or counselor without more education. England (2010) suggests if it weren't for the "glass ceiling" in traditional female occupations, women would stay in their line of work instead of changing to a male-dominated field. This occupational change more often than not forces women to move backwards on the ladder of success, starting again in a new field.

Currently, desegregation has stalled in the workforce. Women are becoming lawyers, doctors, and accountants, but remain underrepresented in science, technology, engineering and mathematics (STEM). Even when women earn STEM degrees, they do not enter traditional STEM jobs after graduation. For instance, in 2014, 74 percent of STEM graduates did not work in STEM occupations, and these individuals tended to be women, and men continue to be overrepresented in engineering and computer science (Census Bureau, 2014). Since STEM occupations require specific degrees, researchers suggest this segregation occurs early on in educational careers (Correll, 2001). For example, by high school, boys are more likely than girls to show an interest and be enrolled in advanced math and science classes (Correll, 2001). These educational paths may lead boys into occupations with all-day access to technology, even for personal use, and girls into helping professions with less time for online engagement. Though the focus of our current study is how this occupational segregation may result in technology access gaps, we also want to push social scientists to think more about how gendered occupations influence political engagement (e.g. the large teachers strikes occurring across the United States, generally led by women).

\section{Technology at Work}

When women started to enter the workforce, they transitioned into and subsequently dominated the service industry and helping-related jobs. With traditional hours and the availability of part-time or full-time employment, women felt the service industry offered them the balance of work and home life they desired (Waldman \& McEddy, 1974). As mentioned previously, women are 
still clustered in the traditional female "service" occupations where they serve as nurses, teachers, social workers, and physical therapists (Hegewisch et al., 2010). Given the fact that these professions deal with people directly, women may be more likely to spend most of their workday engaging in face-to-face conversations and less of their time utilizing technological devices.

We suspect that these service or people-oriented positions come with less access to personal internet use/political news on the job. A useful starting point for understanding digital access by occupation entails narrowing down which professions use the most technology in day-to-day tasks and to what extent professions allow for the recreational use of the internet and/or email while on the job. A Pew Research report (2014) examined which occupations rely the most on technology usage throughout the day. Online users were separated into office-based and non-office-based work, which included service work, and they found that internet and email were more important to certain workforce sectors than others. People who worked in an office were three times as likely to choose usage of email (78\% versus 25\%) and two times more likely to choose internet (68\% versus $25 \%)$ as being very important to their job (Pew Research 2014).

Importantly, even if women are able to achieve a high-status job with access to technology, women often feel pressure to show stronger work commitment in their labor; therefore, they tend to engage less in workplace leisure activities, such as non-work-related computer use. In a study of social norms and employee attitudes, Moody and Siponen (2013) find that employees are more influenced by the benefits of recreational internet use at work than by the penalties, and the more their peers engage in this behavior, the more likely they follow. This same logic can be applied to how people think about and discuss politics and whether or not they engage in this behavior in the workplace. Connecting these behaviors to gender and status, Garrett and Danziger (2008) demonstrate that those in higher career positions use the internet at work more often than those in lower status positions. Since men use the internet for more leisure activities (Garrett \& Danziger, 
2008) and are often found to be in higher ranking positions, this would explain why males, on average, report engaging in more counterproductive computer use at work than women (Everton, Mastrangelo, \& Jolton, 2005).

Women may use the internet just as much as men, but they may not be using it for the same things. Women use the internet more for communication, and men more for searching (Jackson, Ervin, Gardner \& Schmitt, 2001). Women were the early adopters of social media, and there still continues to be a gender gap in social media use (Pew Research Center, 2018). Women tend to use their leisure time going through social media networks and connecting on sites such as Facebook, Instagram, and Pinterest while men search sites such as Twitter and Reddit. Women tend to use social media for social connections and personal interest rather than for news so even though they use social media at higher rates than men, they are being exposed to different information (Pew Research Center, 2018). Due to the fact that men and women already use the internet differently from each other, and women generally tend to consume less news than men (Poindexter, Meraz, \& Weiss, 2008), it is difficult to know if given the opportunity to engage in "cyberslacking" at work, women will use it to seek out political content. Instead, women may use their time at work to either perform their job duties or communicate with others when they can spare a moment.

\section{Political Knowledge and Access to Information}

Increased access to technology and information in the workplace brings about opportunities for people to frequently access the internet and social media platforms on their phones and computers. We expect that access to technology and information will not be equally distributed along gender lines due to differences in job requirements and expectations. For individuals who have more time during their work day to access information, we expect that increased opportunities for accessing political information will subsequently relate to higher levels of political knowledge. 
Political knowledge is often described as a cornerstone construct of political science (Mondak, 2001) and the "currency of democratic citizenship" (Delli Carpini \& Keeter, 1996, p. 8). The typical measures of political knowledge focus on factual knowledge related to key political actors, the basics of public policy issues, and the rules of politics (Delli Carpini \& Keeter, 1996; Lupia, 2016). Thus, typical survey batteries measuring political knowledge ask questions like who the chief justice of the Supreme Court is, who are the primary beneficiaries of Medicaid programs, and the votes required to override a veto. ${ }^{\mathrm{i}}$

The relationship between online information access and political knowledge remains up for debate. Increased access to technology, information, and political news has not necessarily brought about a widespread increase in the American public's political knowledge (Prior 2007). For example, some scholars argue that social media use does not lead to increased political knowledge (Richey \& Zhu, 2015; Shehata, Hopmann, Nord, \& Hoijer, 2015). Lower barriers for accessing information does not necessarily equate to increased attention to political information (Dunaway, Searles, Sui, \& Paul, 2018). Additionally, unlike actively seeking political information, incidental exposure to political information via social media may not lead to increased political knowledge (Gil de Zúñiga, Weeks, \& Ardèvol-Abreu, 2017). Yet, others demonstrate that a reliance on the internet and social media has the capacity to increase specific types of knowledge, such as knowledge about presidential debates (Gottfried, Hardy, Holbert, Winneg, \& Jamison, 2017). Generally, the effects of the relationship between internet use and political knowledge are dependent on individual characteristics like age and education (Yoo and Gil de Zúñiga, 2014), media behaviors like clicking on and sharing information (Beam, Hutchens, \& Hmielowski, 2016), and device type (Dunaway, Searles, Sui, \& Paul, 2018). How useful online access is for political knowledge also varies based on the quality of information and ability of users to discern quality sources (Urban \& Schweiger, 2014). Access to 
technology in the workplace may be an additional factor that influences political knowledge, but this relationship has so far remained underexplored.

\section{Gender Gaps in Political Knowledge}

As women have advanced in education, higher status occupations, and thereby higher levels of socioeconomic status, it remains puzzling why gender gaps in political knowledge continue to persist. These gaps in knowledge remain well-documented (Dow 2011; Sabonmatus 2003; Verba, Burns, \& Schlozman 1997) with men generally scoring better on the typical battery (Delli Carpini \& Keeter 1996) of political knowledge survey items. Yet, scholars have creatively and thoughtfully explored this phenomenon, by suggesting that factors like differential uncertainty, construction of response options for knowledge questions, and propensity to guess on political knowledge survey questions result in men appearing to have higher levels of political knowledge compared to women (Lizotte \& Sidman, 2009; Mondak \& Anderson, 2004). ${ }^{\text {ii }}$ Others focus on exploring knowledge beyond the typical knowledge battery by examining differences in knowledge domains (Eveland \& Hively, 2009) and differences in knowledge levels based on knowledge types (i.e. gender relevant political knowledge such as women's representation in Congress) (Dolan, 2011). Additionally, scholars have examined how people perceive political knowledge of people in their social networks and find differences in perceived expertise with women perceived to be less knowledgeable than men (Huckfeldt \& Sprague, 1995; Mendez \& Osborn, 2010). Taken together, these findings suggest that although gender gaps persist, some of these gaps are due to methodological approach, like question format and available response options, but also different socialization processes, such as perceptions of expertise and aversion to risk, that influence men and women.

For the purposes of our study, we are most interested in how information access influences political knowledge. For example, Jerit and Barabas (2017) find that once exposed to political information, women gain ground, and the gap diminishes. We are suggesting that occupation can 
operate as an impediment to information flows, particularly when it comes to digital access. Thus, increased access to technology at work could lead to higher levels of political knowledge while less access and increased digital segregation could result in decreased levels of political knowledge.

\section{Data and Method}

To test our expectations regarding access to technology at work in political knowledge, we turn to two nationally represented surveys - the General Social Survey (GSS) and American National Election Study (ANES). iii These surveys are the largest, publicly available datasets to contain the same U.S. Census Occupational codes, a technology use variable, and political measures. As the most widely used datasets in the social sciences, we also wished to demonstrate how other scholars could leverage occupation in other questions of interest. To our knowledge, this is the first study of its kind to develop an occupational tech use measure in one dataset to be used to generate a comparable variable in another dataset that does not have a technology measure. In the 2014 wave of the GSS, the instrument included the following question: "During a typical week, about what percentage of your total time at work would you normally spend using different types of electronic technologies (such as computers, tablets, smart phones, cash registers, scanners, GPS devices, robotic devices, and so on)?” (usetech). Respondents were able to respond with a range of values from zero to one hundred percent. This question provides a unique insight into how the use of technology is permeating the workplace, though it does not distinguish between personal and workrelated use. In total, the 2014 GSS had 2,538 respondents, however, only about half the sample had the opportunity to answer the question about the usage of technology (48.4\%). Of those who provided a response, the mean percentage falls just about the midpoint, with the average subject indicating that they use technology $52.4 \%$ of the time. There are slight deviations based on gender, however. While the mean usetech score for men was $48.6 \%$, women were slightly more inclined to use technology at 56.1\% $(\mathrm{p}<.05)$. 


\section{Insert Figure 1 About Here}

For our purposes, we are interested in how this usetech score is distributed across different occupational classes. The U.S. Census Bureau has created an extremely detailed typology whereby respondents describe the responsibilities of their job and are sorted into an industry code which consists of about three hundred options (Census Bureau, 2017). The authors of the General Social Survey replicate this exact Census code classification. Because the sample size of the GSS is magnitudes of order smaller than the data collected by the Census Bureau, it is necessary to aggregate these industry codes into larger occupational classes, a technique that has been used by other research in the field of workplace behavior (Garrett and Danzinger 2008). Using these 10 occupational classes, Garrett and Danziger (2008) created a dichotomous variable of high-status occupations (management, business, financial, or professional) with all other job classes forming the reference category. The broader literature indicates those in higher status occupations have more access to the internet.

\section{Insert Figure 2 About Here}

Figure 2 visualizes the mean of usetech for each of the 10 occupational classes that are available in the General Social Survey, with all missing values removed. Notice that the two occupations in which people use the most technology (technology, engineering, and science along with management) also were classified as high technology use by previous scholarship. For the other two job classifications previously cited as heavy tech use -- health and technology and education, legal and media -- the GSS usetech mean is in the middle of the range. In addition, both office and administrative support, along with sales occupations, use technology approximately $2 / 3$ of the time. This may be reflective of the rapid increase in the use of technology in certain occupations, since previous scholarship was based on data collected over a decade ago. The other major takeaway from these results is that there is not a clear means to create a dichotomous variable for high tech usage 
and low-tech usage occupational classes. Instead, a more statistically precise approach to understanding technology usage by occupation would be to use the mean scores for each occupational class as a continuous variable. This has the advantage of maintaining the real distance between job classes.

\section{Insert Figure 3 About Here}

Is usetech unevenly distributed in occupational classes by gender? Figure 3 displays the differences between men and women in each of the 10 Census job classifications, as well as 95\% confidence intervals for each estimate indicated by capped vertical lines. Speaking generally, women use technology more than their male counterparts when working in the same occupational field. The notable exception to that is education, legal, and media fields, where men use more technology (statistically significant). This is likely the case as more female respondents are in teaching professions, which had a lower level of usetech, while men made up a greater proportion of the legal field. There are some fields where female technology usage far outstrips that of males. For instance, in office and administrative support, women use technology approximately $25 \%$ more than men. A similar gap exists between men and women in the military. However, across all 10 occupational classifications, the difference between the genders is not statistically significant in most cases. Of the three with statistically different means, men only use technology more in one occupational area (education, legal, and media) while women utilize technology more in management and office and administrative support.

While the GSS affords researchers this invaluable insight into the frequency of technology in the workplace, it does not provide the necessary questions for scholars to try and link this usetech variable with important political outcomes, most notably an increase in political knowledge. In addition, by transferring the usetech/occupational classifications to another dataset, we are avoiding generating hypotheses and testing them in the same data. Fortunately, the American National 
Election Study contains both the Census occupational codes and five political knowledge questions, which have been used in numerous other studies (Delli Carpini \& Keeter, 1996; Mondak, 2001). To link these two surveys together, we generated a new variable in the ANES dataset that transferred the mean usetech GSS score for each of the 10 occupational groups into which ANES participants fell.

\section{Insert Figure 4 About Here}

Before moving to more sophisticated analyses, it is valuable to understand how political knowledge is distributed across both genders without any controls. Figure 4 indicates the distribution of political knowledge for both men and women. Each group was asked five questions ranging from easy: "Who is the current vice president of the United States?" to difficult: "Who is the current chief justice of the United States Supreme Court?"iv Importantly because of previous findings on men being more likely than women to "guess," the answers were multiple choice, and a “don't know" option was not presented to respondents. Approximately $8.6 \%$ of the female respondents were unable to correctly answer a single question, compared to about 5.1\% of men. At the top end of the range, $32.8 \%$ of men were able to answer at least 4 questions correct, while $25.7 \%$ of women were able to do the same. The mean number of correct answers for men was 3.16, and for women, $2.74(p<.05)$. These results indicate that women have lower levels of political knowledge, but is the use of technology a way to overcome that deficit in some scenarios?

Insert Figure 5 About Here

Figure 5 displays a simple linear relationship between the usage of technology on the $x$-axis and the number of knowledge questions answered correctly on the y-axis. Note that for both men and women, the relationship is positive and significant (coefficient for men $=.197$, women $=.171, \mathrm{p}<$ $.00)$ in that the more an individual uses technology at their job, the more likely they are to evince 
higher levels of political knowledge. Consider however, that the y-intercept for males in the sample is nearly $10 \%$ higher, which is indicative of the knowledge literature previously described. While the relationship between these two variables is slightly more positive for males, the gain in knowledge between the two genders is relatively small (just .03 on a scale from $0-5$ ).

In order to further isolate the relationship between using technology and political knowledge, an OLS regression was specified with political knowledge as the dependent variable. The previously used item usetech was included as well as a question that asks how many days a week an individual watches, reads, or listens to news besides sports. In addition, the ANES asks individuals, "How often do you pay attention to what's going on in government and politics?" They were then given five response options ranging from "Never" to "Always" with "About half of the time" as the middle option. In addition, a number of controls were added including: highest level of education completed, a dichotomous variable indicating whether a respondent has children under the age of 18 at home, and income (Delli Carpini \& Keeter, 1996; Hillygus, 2005; McLeod \& Perse, 1994; Tichenor, Donohue, \& Olien, 1970). All variables were scaled from zero to one to aid in interpretation. Because of the standardization technique, each coefficient is showing the full effect of each variable (for instance the estimate for education is going from lacking a high school diploma to having a graduate degree). The data was divided into a male-only sample and a female-only sample as means to determine if these variables work in different ways for men and men. The results of the regression are displayed in a coefficient plot in Figure 6. The interpretation of the plot is straightforward: if one of the colored horizontal lines intersects with the vertical solid line on 0 , then the variable is not statistically significant. However, if there is no intersection, and it is to the right of the solid line on zero, that indicates greater political knowledge. If it's to the left of the solid line, it means less political knowledge.

Insert Figure 6 About Here 
The first finding is the most striking: these variables, by and large, do not work in different ways for men than they do for women. One important exception to this is news consumption, where the relationship is statistically significant and positive for men but is not statistically significant for women. This regression result indicates that the more days a week that men consume news, the more likely they are to gain political knowledge, while the same is not true for women. Of the other variables included, only one (having children) drives down political knowledge, but the effect reaches statistical significance only for women. This comports with previous work on the so-called "second shift" problem that has appeared in other research (Hochschild 1989; Blair-Loy et al. 2015). Three of the other variables (political interest, education, and income) are all positively related to political knowledge. Unsurprisingly, political interest and education are the two factors that are the strongest drivers of political knowledge (Barabas, Jerit, Pollock, \& Rainey, 2014; Delli Carpini \& Keeter, 1996; Price \& Zaller, 1993). Consider the fact that moving from the lowest level of education to the highest moves an individual up 2.3-2.4 questions on the political knowledge scale, all else being held equal. Income has a positive effect as well, but it is much smaller. ${ }^{\mathrm{v}}$

The variable of interest for this study, the amount of technology used in the workplace, is not a significant predictor. While the coefficient is positive, the standard errors leave open the possibility that the effect could potentially be negative. ${ }^{\mathrm{vi}}$ It is worth pondering why this is the case. Obviously, there is a great deal of correlation between many of the variables. For instance, education and the usage of technology at work are correlated at .36, which provides support for the theory that greater levels of education lead individuals into white collar careers that typically involved significant usage of technology (a visualization of these correlations is available in the appendix). When a regression model is specified that omits the control for education, the use of technology becomes statistically significant and predicts more political knowledge (shown in the appendix). Therefore, it seems as if the impact of technology usage is strongly related to the level of education of individuals. 
Undoubtedly, this relationship can be impacted by a number of factors, with variables such as political interest playing a role in how much an individual cares to learn about politics. As previously mentioned, the ANES asks respondents about their political interest. To create a dichotomous variable of political interest, individuals who responded to this question with the two lowest options were classified as "Low Interest," while those who responded with one of the top three choices were put into the "High Interest" category. A marginal effects model was specified for both men and women that interacted the amount of technology they used at their jobs with how interested they were in day-to-day politics, with controls for income, having children, education, and news consumption included. The results of this model are displayed in Figure 7.

\section{Insert Figure 7 About Here}

When looking at just those with low interest in following politics, there is an upward slope in the line moving from left to right, however the gain in political knowledge is much larger for men than for women. For men with low political interest, they gain nearly .8 of a question correctly as they use more technology at work, but for the same group of women, the gain is approximately half of one question. For those of high interest, both genders see substantively large gains in political knowledge moving from the low part of the usetech scale to the higher end. However, even at the far right end of the scale, there is a large gap between how much political knowledge men possess (3.2 questions correct) versus women (2.85 questions correct). Notice that at all levels of usetech, men have higher levels of political knowledge than women, and the gap does not narrow moving across the x-axis. The real story is, as previously mentioned, the y-intercept. Men consistently have a higher baseline of political knowledge than women, and the usage of technology does not narrow this gap.

There is much to consider from these results. There is not a negative relationship between using technology at work and political knowledge; in fact, in all four cases studied here, the more 
technology that one uses, the more political knowledge is gained. The relative amount of political knowledge that is gained for each of the four groups is consistent as well. However, another way to look at these results is: technology usage is not narrowing the gap for those of low interest. For those who are highly politically interested, the "rich" are getting "richer" at the same rate. For both men and women, there is a gain in knowledge, however that gain in knowledge is slightly greater for men than women. These results provide evidence that technology usage increases political knowledge for both genders, across levels of interest.

\section{Insert Figure 8 About Here}

One other possibility is worth exploring: consumption of news. As previously described, the ANES asks respondents, "During a typical week, how many days do you watch, read, or listen to news on TV, radio, printed newspapers, or the internet, not including sports?" Response options range from none to seven days a week. The sample was broken into those with low consumption (four days a week or less) and those with high consumption (five to seven days a week), and this was interacted with the usetech variable. Figure 8 is a margins plot of this interaction. Here the results are much different than the interaction between political interest and usetech. While there is clearly a positive relationship between usetech and political knowledge when broken down by political interest, news consumption generates no statistically significant relationship for either men or women, regardless of if they indicated high or low media consumption. The effects here are especially modest, with low consumption men and women gaining less than a quarter of a question moving across the x-axis. It is notable that for the female sample, there is not a statistically significant difference in gaining political knowledge between those who consume a great deal of news media and those who consume much less of it. Again, however, the $y$-intercepts are instructive here. Men consistently start at a higher baseline of political knowledge, and news media consumption is not narrowing this gap as one uses more technology at work. 


\section{Discussion}

Social scientists continue to uncover the nuanced ways in which men and women differ in their political knowledge and interest. We wish to add to that discussion by examining access to technology in a societal area often segregated by gender - the workplace. From our data, it appears technology access does not contribute to the gender gap in political engagement; rather, other psychological and social factors may lead women to use work technology for other purposes (Jackson, Ervin, Gardner \& Schmitt, 2001; Poindexter, Meraz, \& Weiss, 2008). Avoiding political content online, then, may have more to do with the inherent conflict in politics, and women tending to be higher than men on conflict avoidance (Brooks, 2010; Ulbig and Funk, 1999; Djupe, McClurg and Sokhey, 2016; Wolak and McDevitt, 2011). It is also possible women are accessing political information that does not conform to the knowledge battery included in the ANES but is policy or domain specific (Eveland \& Hively, 2009). Future research should explore how the different ways of knowing politics is distributed across access to technology at work. For example, social workers, health workers and teachers are likely very knowledgeable about policies across these areas and may use their technological access to read stories on these matters but may be less interested in naming people in positions of power.

In general, there is very little work in social science about the role of political information access in the workplace, particularly via technological resources. Of the workplace studies that have been conducted, most focus on in-person social networks at work that lead to political discussions or the role of information exposure at work on influencing political attitudes. For example, Banaszak and Leighley (1991) found that women's employment contexts shaped their attitudes towards women's movements. Working in male-dominated fields led to increases in support by women for women's movements (Banaszak \& Leighley, 1991). 
Previous research has uncovered gender differences in political discussion. Men are more likely than women to discuss politics (Huckfeldt \& Sprague, 1995), express opinions (Atkeson \& Rapoport, 2003), and try to influence others (Rapoport, 1981; Hansen, 1997). Men and women’s discussion networks also look different from one another as men overwhelmingly discuss politics with other men (Djupe, McClurg, and Sokhey, 2016). Additionally, women are judged by others in their social networks to be less competent and politically knowledgeable (Huckfeldt \& Sprague 1995). These findings reflect information exposure via political discussions but do not discuss the role of the workplace for these discussions. These gendered patterns in political discussion have the potential to reinforce other gendered gaps in the workplace, particularly in regard to political information exposure through access to technology.

Other studies that assess how the workplace influences political behavior focus on the role of workplace life on political participation. For example, Schlozman, Burns, and Verba (1999) find that gender gaps in political participation can be explained by gender differences in workplace experiences while others find that career roles (Elden, 1981) and job autonomy (Jian \& Jeffres, 2008) can influence levels of political efficacy and participation outside of the workplace. Yet, they do not demonstrate how workplace roles or job autonomy influence political knowledge.

Although there have been studies of the workplace environment and political behavior, social science research has generally focused on political behavior generally or in citizens' personal lives. Yet, many people spend a substantial portion of their time each week in the workplace. Recent surveys (McGregor, 2017) indicates widespread increases in accessing political information at work. But these increases will only exist for people who have the opportunity to use technology for nonwork purposes like checking personal emails, perusing news websites, and using social media. Increased attention to these differences could help us further understand the gendered differences we repeatedly find for political behaviors like political knowledge. 
Though class, geography, and aptitudes influence occupation selection, men and women tend to choose different career paths. Through this study, we investigate if women's selection of jobs in the helping profession or with high person-to-person interaction leads to less access to technology, indicating reduced time for consuming online content. This study serves as an exploration of digital segregation using the nationally representative data that are currently available. We were limited by the availability of data that contains occupational codes, political knowledge, political engagement, and technology usage on the job. To further understand how workplace segregation, often based on gender, influences political engagement, social scientists should consider incorporating measures of workplace characteristics into studies of political behavior, rather than focusing just on what happens outside of the workday. Questions of technological access and content of information will be important going forward as people are increasingly spending time at work accessing political information. These increases could further the gap between the knowledge rich and the knowledge poor due to accessibility.

In the end, we find some indications that generally tech use on the job does not seem to be related to political knowledge, other than serving as a proxy of sorts for education. This could help scholars interested in the education connection to think through the mechanisms by which individuals are gaining political knowledge. In addition, the interaction between total media consumption and tech use suggests that when women have an interest in following the news and have access at work, they can outperform men and women who are low media consumers with equal tech use. This may provide more insight into the "higher bar" thesis that suggests women tend to require high levels of knowledge before undertaking political activities (Ondercin \& Jones-White, 2011). Other scholars have noted that typical predictors of knowledge like education vary based on the amount of information in the information environment and mass media (Jerit, Barabas, \& Bolsen, 2006). Additionally, the persistent political knowledge gender gap can be reduced with 
exposure to news and political information (Jerit \& Barabas, 2017). The findings from our study serve as a test case for the information environment theory where access to technology works as a measure of exposure to the information environment. Our study also supplements other research that focuses on how career women gain the social capital necessary for civic skill development and political engagement (Burns, Schlozman, \& Verba 2001). Beyond additional samples with improved measures, future research should also address how to think about further connections between other demographic characteristics like race and class with occupations and personal access to political content in the workplace. Ultimately, if some people are using the workplace as a space for accessing political news and information for substantial periods of time, while others do not have these same opportunities for access, then we may find further gaps in political knowledge based on the occupations that people choose.

\section{Author Biographical Information:}

Amanda Friesen (amfriese@iupui.edu) is an associate professor of political science and faculty research fellow at the Center for the Study of Religion and American Culture at Indiana UniversityPurdue University Indianapolis.

Ryan Burge (rpburge@eiu.edu) is an assistant professor of political science at Eastern Illinois University.

Kylee Britzman (kjbritzman@lcsc.edu) is an assistant professor of political science at Lewis-Clark State College.

Data Availability:

The data used in this study is publicly available data from the American National Election Studies (https://electionstudies.org/) and the General Social Survey (http://gss.norc.org/).

Software Information: 
The analysis for this paper was completed using the $\mathrm{R}$ statistical software program. This analysis was produced with Version 3.5.1. A number of packages were used for this analysis, those include:

tidyverse

car

ggbeeswarm

dotwhisker

prediction

patchwork

jtools

These packages are publicly available on CRAN or through Github.

All code that was used in this analysis will be provided in an online appendix that will be made publicly available upon publication of the manuscript.

\section{References}

Atkeson, L.R. \& Rapoport, R.B. (2003). The More Things Change, the More They Stay the Same: Examining Gender Differences in Political Attitude Expression, 1952-2000. Public Opinion Quarterly, 67(4), 495-521.

Banaszak, L.A. \& Leighley, J. (1991). How Employment Affects Women’s Gender Attitudes as a Locus of Contextual Effects. Political Geography Quarterly, 10(2), 174-185.

Barabas, J., Jerit, J., Pollock, W., \& Rainey, C. (2014). The Question(s) of Political Knowledge. American Political Science Review, 108(4), 840-855.

Beam, M. A., Hutchens, M.J., \& Hmieloski, J.D. (2016). Clicking vs. Sharing: The Relationship between Online News Behaviors and Political Knowledge. Computers in Human Behavior, 59, 215-220.

Blair-Loy, M., Hochschild, A., Pugh, A.J., Williams, J.C., \& Hartmann, H. (2015). Stability and transformation in gender, work, and family: insights from the second shift for the next quarter century. Community, Work \& Family, 18(4), .435-454. 
Brooks, D. J. (2010). “A negativity gap? Voter gender and attack politics in American elections." Politics and Gender 6(3), 319-341.

Burns, N., Schlozman, K.L., \& Verba, S. (2001). The Private Roots of Public Action: Gender, Equality, and Political Participation. Cambridge, MA: Harvard University Press.

Census Bureau. (2014). “Census Bureau Reports Majority of STEM College Graduates Do Not Work in STEM Occupations." United States Census Bureau. https://www.census.gov/newsroom/press-releases/2014/cb14-130.html.

Census Bureau. (2017). "Industry and Occupation.” United States Census Bureau. https://www.census.gov/topics/employment/industry-occupation/about/occupation.html Correll, S. (2001). Gender and the Career Choice Process: The Role of Biased Self-Assessments. American Journal of Sociology, 106 (6), 859-884.

Delli Carpini, M., \& Keeter, S. (1996). What Americans Know about Politics and Why It Matters. Yale University Press.

Dolan, K. (2011). Do Women and Men Know Different Things? Measuring Gender Differences in Political Knowledge. The Journal of Politics, 73(1), 97-107.

Djupe, P., McClurg, S., \& Sokhey, A.E. (2016). The Political Consequences of Gender in Social Networks. British Journal of Political Science, 48(3), 637-658.

Dunaway, J., Searles, K., Sui, M., \& Paul, N. (2018). News Attention in a Mobile Era. Journal of Computer-Mediated Communication, 23(2), 107-124.

Elden, J. M. (1981). Political Efficacy at Work: The Connection between More Autonomous Forms of Workplace Organization and a More Participatory Politics. American Political Science Review, 75(1), 43-58.

England, P. (2010). The Gender Revolution: Uneven and Stalled. Gender and Society, 24(2), 149- 
166.

Eveland, W., \& Hutchens Hively, M.H. (2009). Political Discussion Frequency, Network Size, and 'Heterogeneity' of Discussion as Predictors of Political Knowledge and Participation. Journal of Communication, 59(2), 205-224.

Everton, W., Mastrangelo, P., \& Jolton, J. (2005). Personality Correlates of Employees’ Personal Use of Work Computers. CyberPsychology \& Behavior, 8(2), 143-153.

Garrett, R. K., \& Danziger, J. (2008). On Cyberslacking: Workplace Status and Personal Internet Use at Work. CyberPsychology \& Behavior, 11(3), 287-292.

Gil de Zúñiga, H., B. Weeks, \& A. Ardèvol-Abreu. (2017). Effects of the News-Finds-Me Perception in Communication: Social Media Use Implications for News Seeking and Learning about Politics. Journal of Computer-Mediated Communication, 22(3), 105-123.

Gottfried, J., Hardy, B., Holbert, R.L., Winneg, K. \& Jamieson, K.H. (2017). The Changing Nature of Political Debate Consumption: Social Media, Multitasking, and Knowledge Acquisition. Political Communication, 34(2), 172-199.

Hansen, S. (1997). Talking about Politics: Gender and Contextual Effects on Political Proselytizing. Journal of Politics, 59(1), 73-103.

Hegewisch, A., Liepmann, H., Hayes, J., \& Hartmann, H. (2010). Separate and Not Equal? Gender Segregation in the Labor Market and the Gender Wage Gap. Institute for Women's Policy Research, 377, 1-15.

Hillygus, D.S. (2005). The MISSING LINK: Exploring the Relationship between Higher Education and Political Knowledge. Political Behavior, 27(1), 25-47.

Hochschild, A. (1989). The Second Shift: Working Parents and the Revolution at Home. New York, NY: Viking.

Huckfeldt, R., \& Sprague, J. (1995). Citizens, Politics, and Social Communication: Information and Influence in 
an Election Campaign. New York: Cambridge University Press.

Jackson, L., Ervin, K., Garnder, P., \& Schmitt, N. (2001). Gender and the Internet: Women Communicating and Men Searching. Sex Roles, 44(5/6), 363-379.

Jerit, J., \& Barabas, J. (2017). Revisiting the Gender Gap in Political Knowledge. Political Behavior, 39(4), 817-838.

Jian, G., \& Jeffres, L.W. (2008). Spanning the Boundaries of Work: Workplace Participation, Political Efficacy, and Political Involvement. Communication Studies, 59(1), 35-50.

Kuklinski, J.\& Quirk, P. (2001). Conceptual Foundations of Citizen Competence. Political Behavior, 23(3), 285-311.

Lizotte, M.K. \& Sidman, A.H. (2009). Explaining the Gender Gap in Political Knowledge. Politics \& Gender, 5(2), 127-151.

Lupia, A. (2016). Uninformed: Why People Know So Little about Politics and What We Can Do About It. Oxford University Press.

Mandel, H., \& Semyonov, M. (2016). Going Back in Time? Gender Differences in Trends and Sources of the Racial Pay Gap, 1979 to 2010. American Sociological Review, 81(5), 1039-1068.

McGregor, J. (2017, February 7). Since the election, a third of workers say their colleagues talk about politics more than work. The Washington Post.

McLeod, D.M. \& Perse, E.M. (1994). Direct and Indirect Effects of Socioeconomic Status on Public Affairs Knowledge. Journalism \& Mass Communication Quarterly, 71(2), 433-442.

Mendez, J.M., \& Osborn, T. (2009). Gender and the Perception of Knowledge in Political Discussion. Political Research Quarterly, 63(2), 269-279.

Mondak, J.J. (2001). Developing Valid Knowledge Scales. American Journal of Political Science, 45(1), 224-238.

Mondak, J.J., \& Anderson, M.R. (2004) The Knowledge Gap: A Reexamination of Gender-Based 
Differences in Political Knowledge. The Journal of Politics, 66(2), 492-512.

Moody, G. D., \& Siponen, M. (2013). Using the Theory of Interpersonal Behavior to Explain NonWork-Related Personal Use of the Internet at Work. Information \& Management, 50(6), 322335.

Mutz, D., \& Mondak, J.J. (2006). The Workplace as a Context for Cross-Cutting Political Discourse. Journal of Politics, 68(1), 150-155.

Ondercin, H L., \& Jones-White, D. (2011). Gender Jeopardy: What is the Impact of Gender Differences in Political Knowledge on Political Participation? Social Science Quarterly, 92(3), 674-694.

Pew Research Center. (2014). Technology Impacts on Workers. http://www.pewinternet.org/2014/12/30/technologys-impact-on-workers/

Poindexter, P., Meraz, S., \& Weiss, A.S. (2007). Women, Men and News: Divided and Disconnected in the News Media Landscape. Routledge.

Price, V., \& Zaller, J. 1993. Who Gets the News? Alternative Measures of News Reception and Their Implications for Research. Public Opinion Quarterly, 57(2), 133-164.

Prior, M. (2007). Post-Broadcast Democracy: How Media Choice Increases Inequality in Political Involvement and Polarizes Elections. New York: Cambridge University Press.

Rapoport, R. (1981). The Sex Gap in Political Persuading: Where the 'Structuring Principle' Works. American Journal of Political Science, 25, 32-48.

Ridgeway, C. (2009). Framed Before We Know It: How Gender Shapes Social Relations. Gender and Society, 23(2), 145-160.

Richey, S. \& Zhu, J. (2015). Internet Access Does Not Improve Political Interest, Efficacy, and Knowledge for Late Adopters. Political Communication, 32(3), 396-413.

Sabonmatsu, K. (2003). Gender-Related Political Knowledge and the Descriptive Representation of 
Women. Political Behavior, 25(4), 367-388.

Schlozman, K.L, Burns, N., \& Verba, S. (1999). “What Happened at Work Today?’: A Multistage Model of Gender, Employment, and Political Participation. Journal of Politics, 61(1), 29-53.

Sias, P. \& Cahill, D. (1998). From Coworkers to Friends: The Development of Peer Friendships in the Workplace. Western Journal of Communication, 62(3), 273-299.

Shehata, A., Hopmann, D.N., Nord, L. \& Hoijer, J. (2015). Television Channel Content Profiles and Differential Knowledge Growth: A Test of the Inadvertent Learning Hypothesis Using Panel Data. Political Communication, 32(3), 377-395.

Su, R., Rounds, J., \& Armstrong, P. I. (2009). Men and Things, Women and People: A MetaAnalysis of Sex Differences in Interests. Psychological Bulletin, 135(6), 859-884.

Tichenor, P.J., Donohue, G.A., \& Olien, C.N. (1970). Mass Media Flow and Differential Growth in Knowledge. Public Opinion Quarterly, 34(2), 159-170.

Tse, H., Dasborough, M., \& Ashkanasy, N. (2008). A Multi-Level Analysis of Team Climate and Exchange Relationships at Work. The Leadership Quarterly, 19(2), 195-211.

Urban, J. \& Schweiger, W. (2014). News Quality from the Recipients’ Perspective. Journalism Studies, 15(6), 821-840.

Ulbig, S. G., and Funk, C.L. (1999). “Conflict Avoidance and Political Participation.” Political Behavior 21(3), 265-82.

Verba, S., Burns, N., \& Schlozman, K.L. 1997. Knowing and Caring about Politics: Gender and Political Engagement. Journal of Politics, 59(4), 1051-1072.

Waldman, E., \& McEddy B. (1974). Where Women Work: An Analysis by Industry and Occupation. Montbly Labor Review, 97 (5), 3-13.

Wolak, J., \& McDevitt, M. (2011). The roots of the gender gap in political knowledge in adolescence. Political Behavior, 33(3), 505-533. 
Yoo, S.W. \& Gil de Zúñiga, H. (2014). Connecting Blog, Twitter, and Facebook

Use with Gaps in Knowledge and Participation. Communication \& Society, 27(4), 33-48. 
Figure 1 - Technology Distribution by Gender 


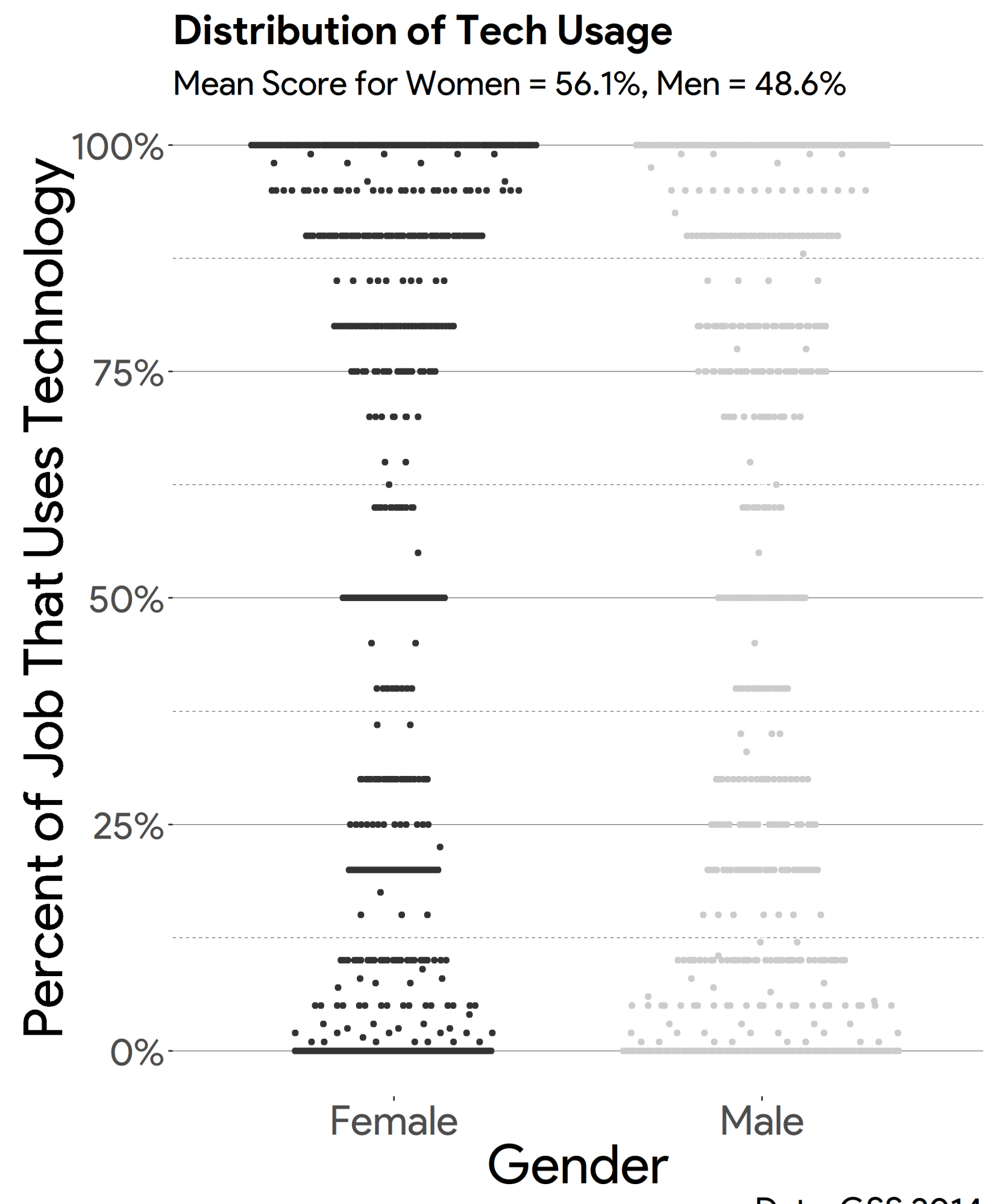

Data: GSS 2014 
Figure 2-Occupational Class and Technology Usage

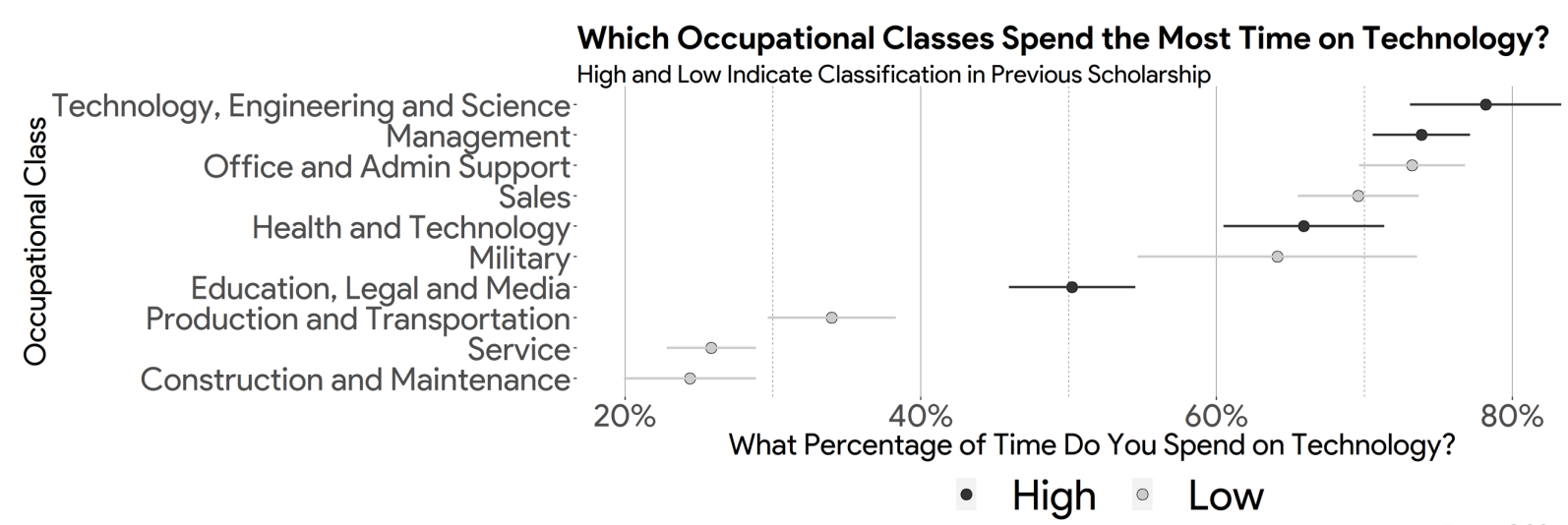

Which Occupational Classes Spend the Most Time on Technology?

High and Low Indicate Classification in Previous Scholarship

Data: GSS 2014 
Figure 3 - The Usage of Technology by Occupation and Gender

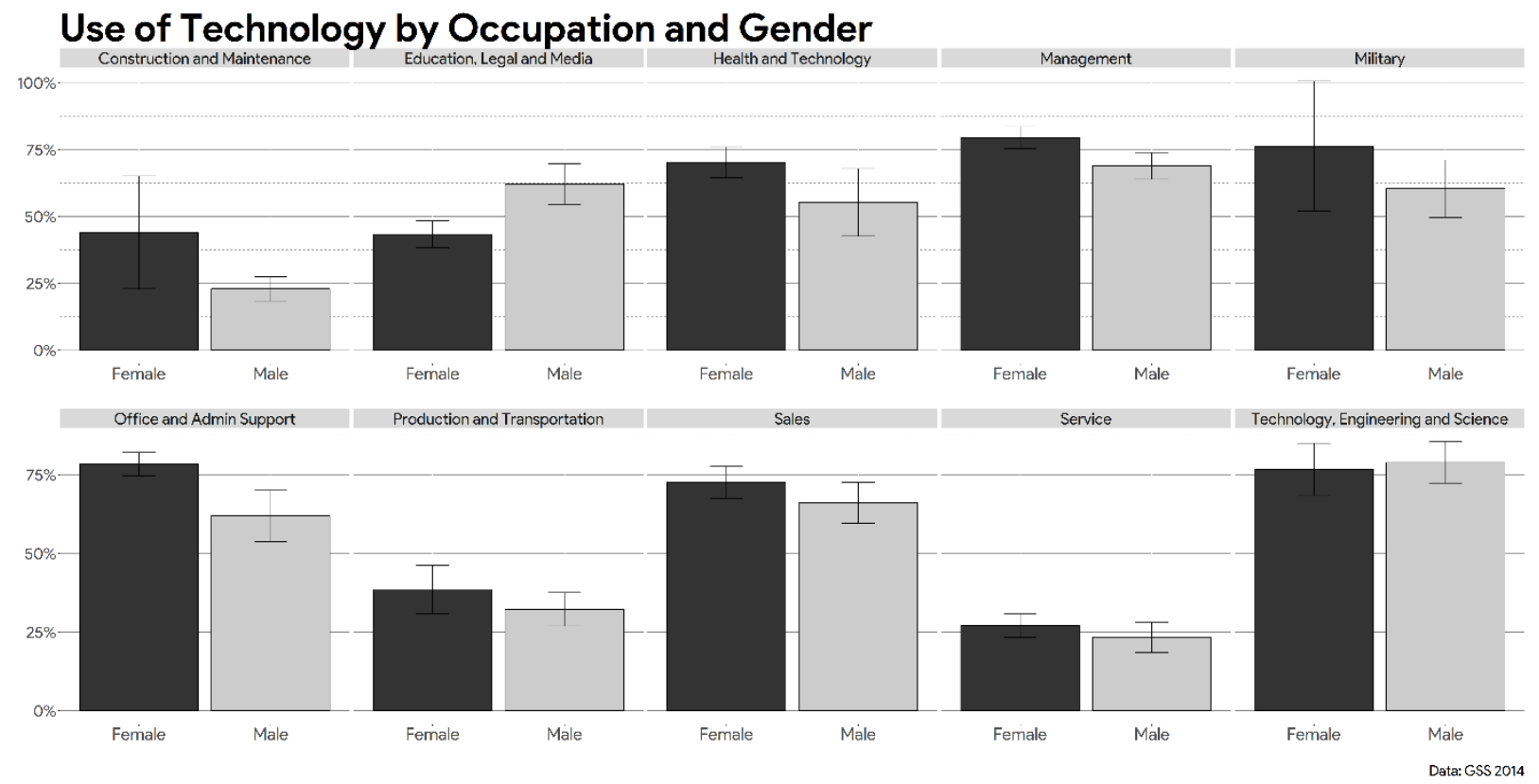


Figure 4-Distribution of Political Knowledge by Gender

\section{Political Knowledge}

Mean Number Correct for Women: 2.74, For Men: 3.16 Female

Male

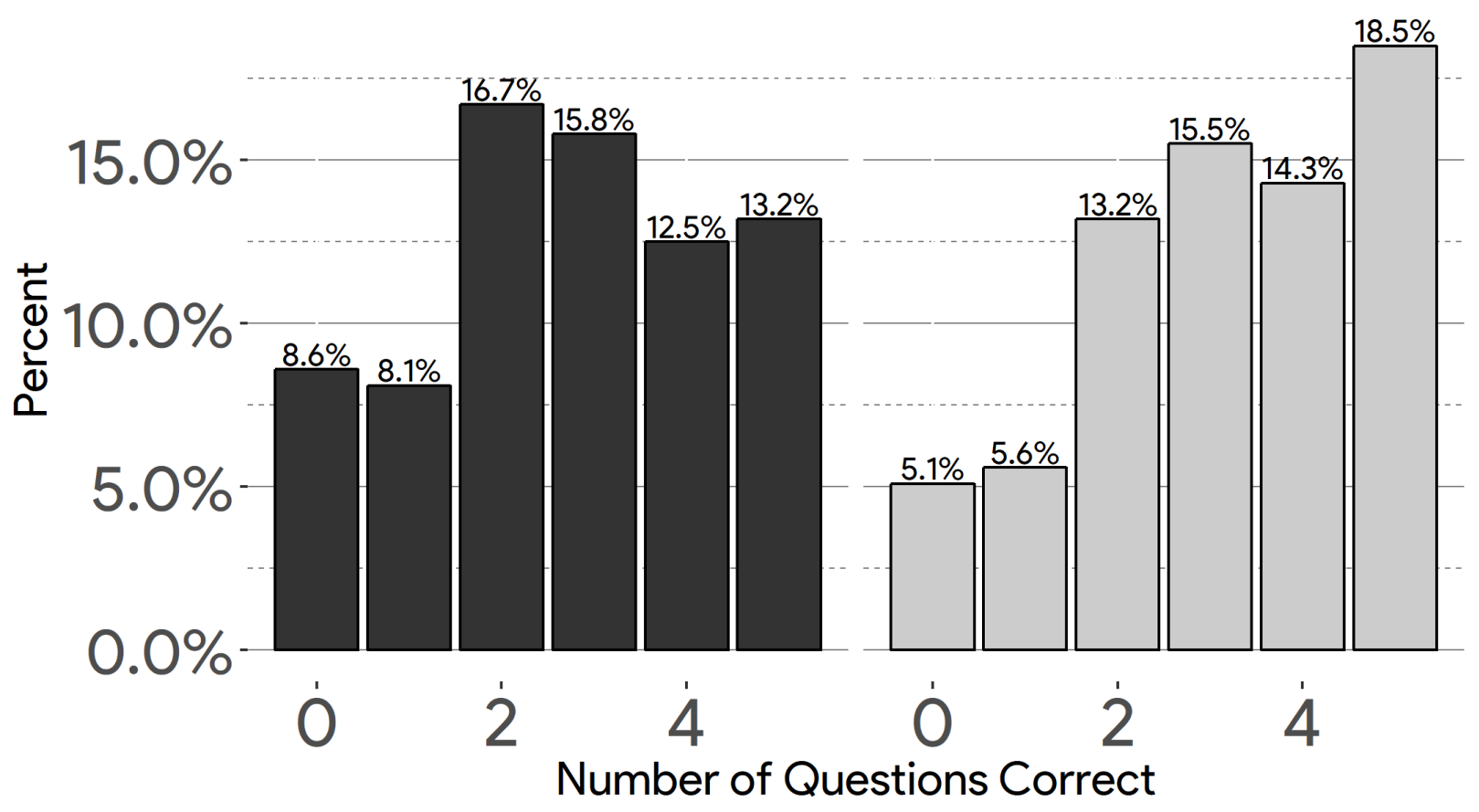


Figure 5 - Political Knowledge and Technology Usage

\section{Political Knowledge Gain by Tech Use}

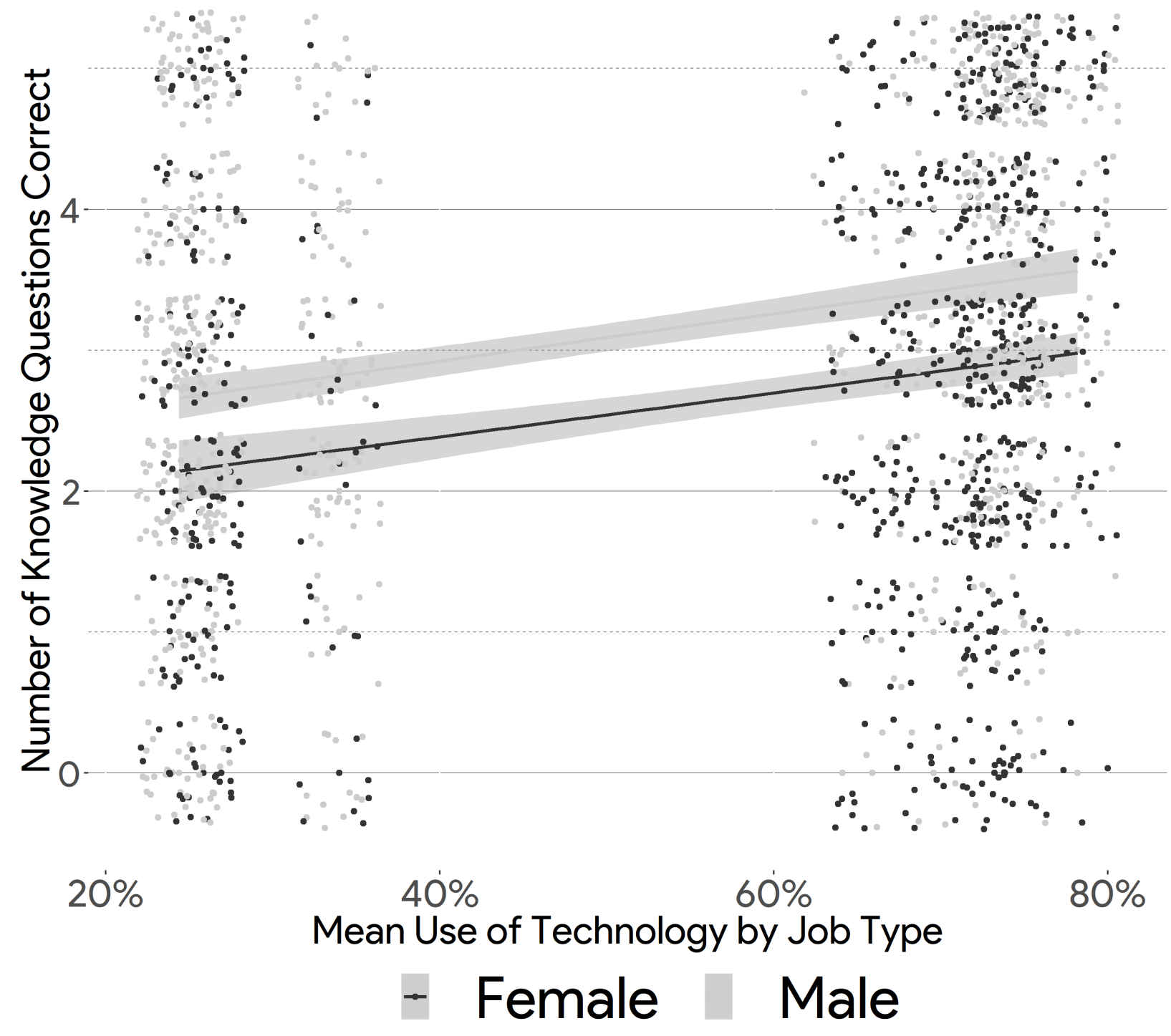

Data: ANES 2016 
Figure 6 - Predicting Political Knowledge Among Both Genders

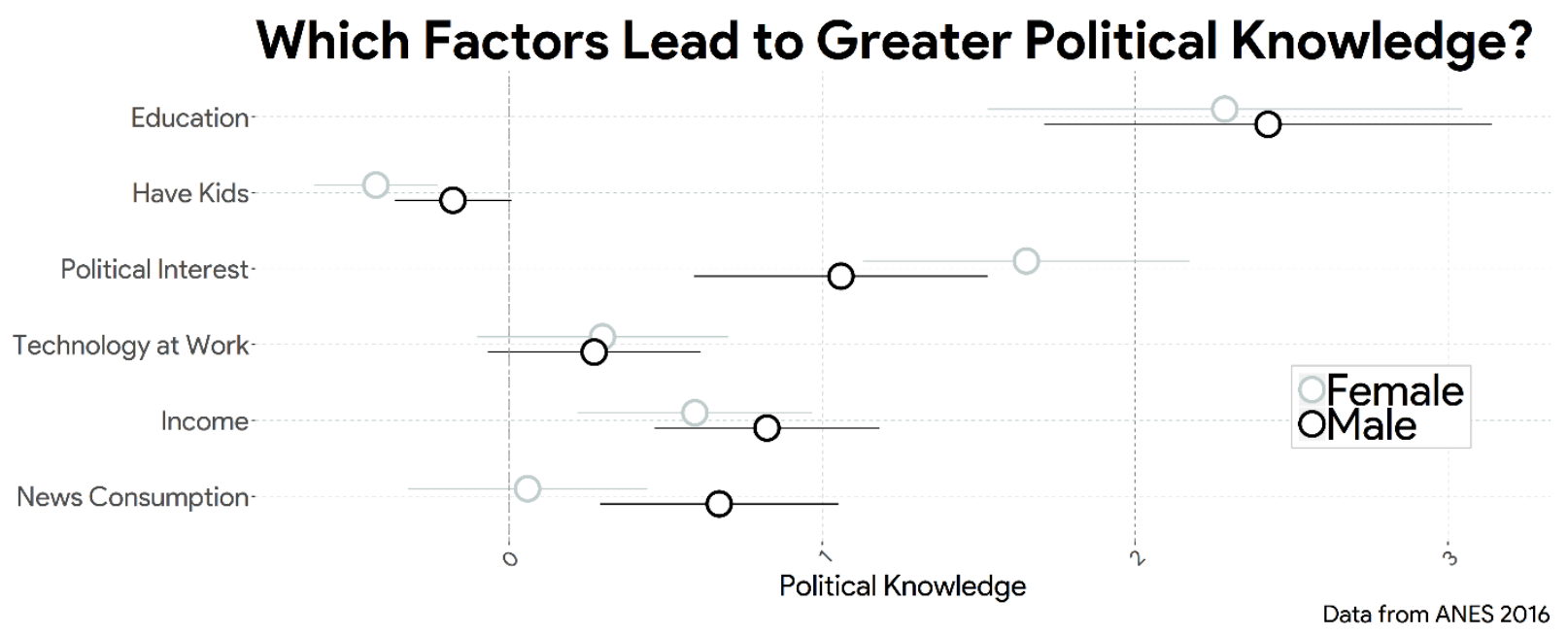


Figure 7 - The Interaction between Political Interest and Technology Use on Political Knowledge

Interaction of Political Interest and Tech Usage on Political Knowledge

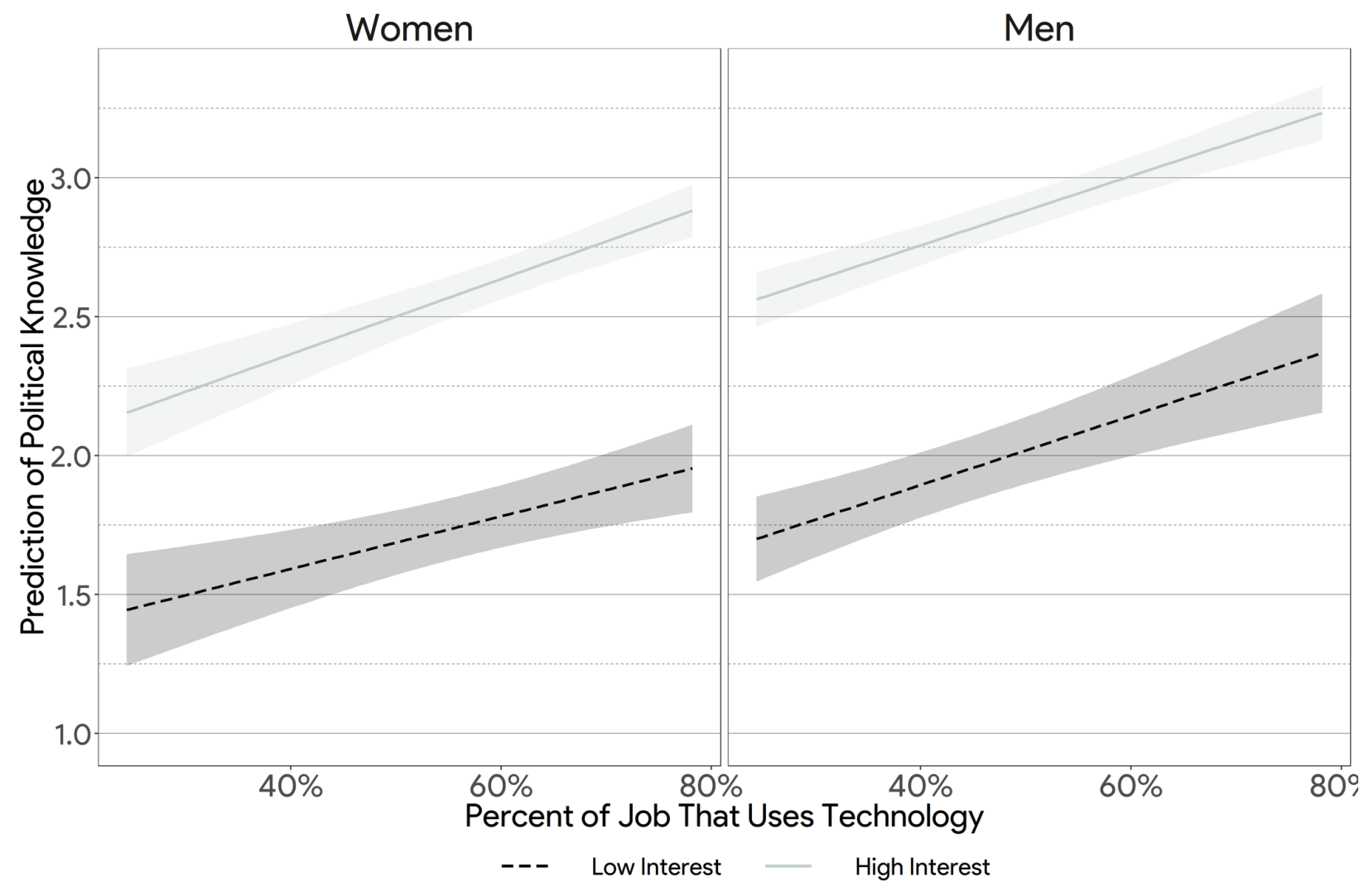


Figure 8 - The Interaction between News Consumption and Technology Usage on Political Knowledge

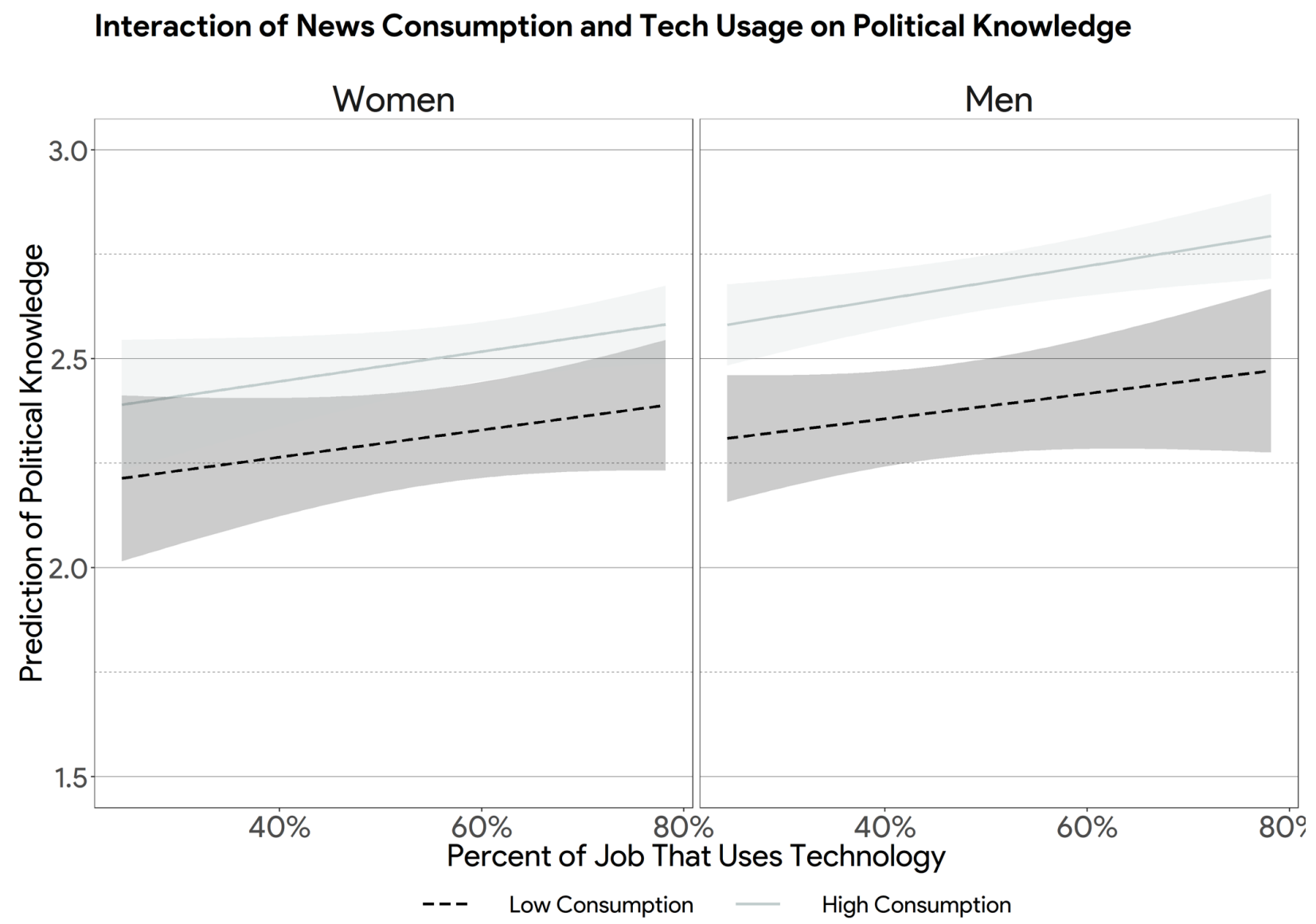


Appendix

Figure A1

\section{Correlation Coefficients}

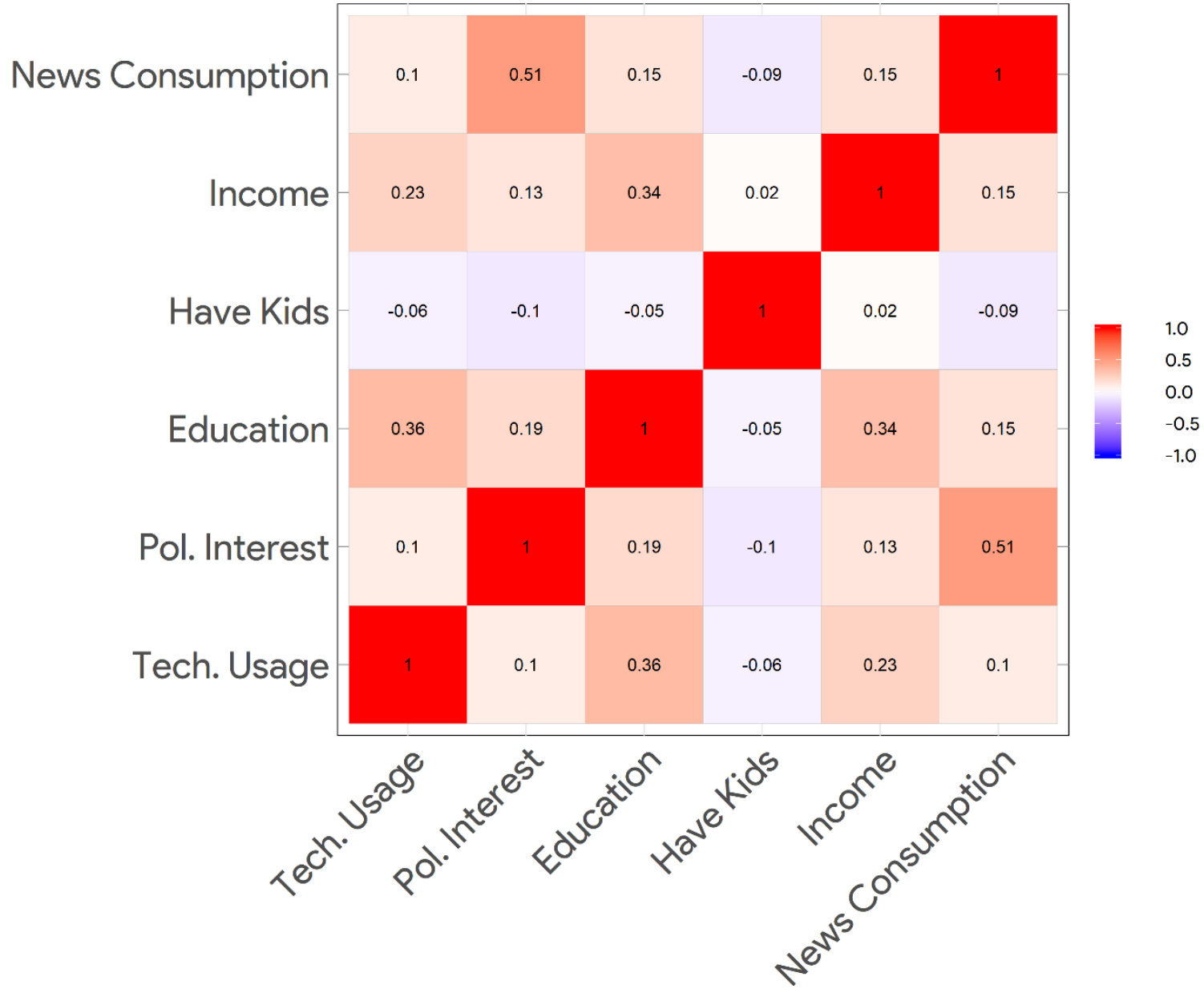


Figure A2

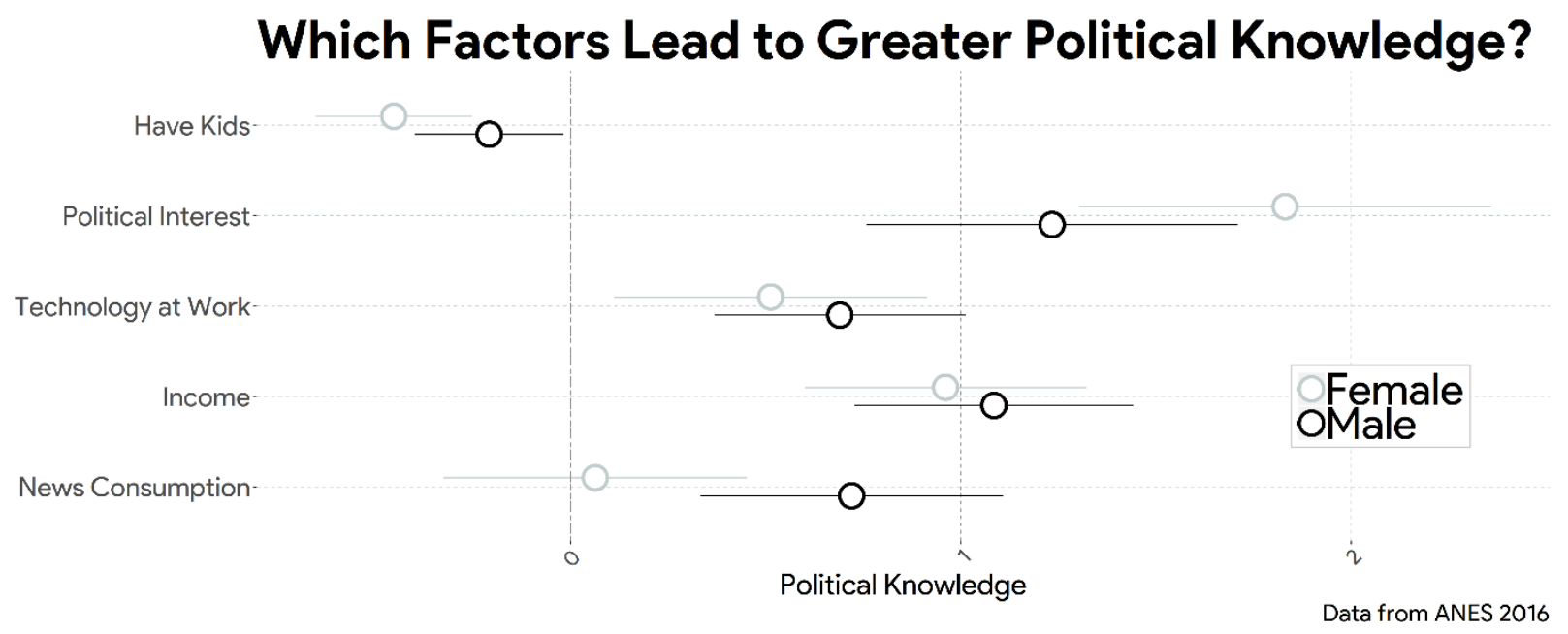


Table A1

Regression Model in Figure 7

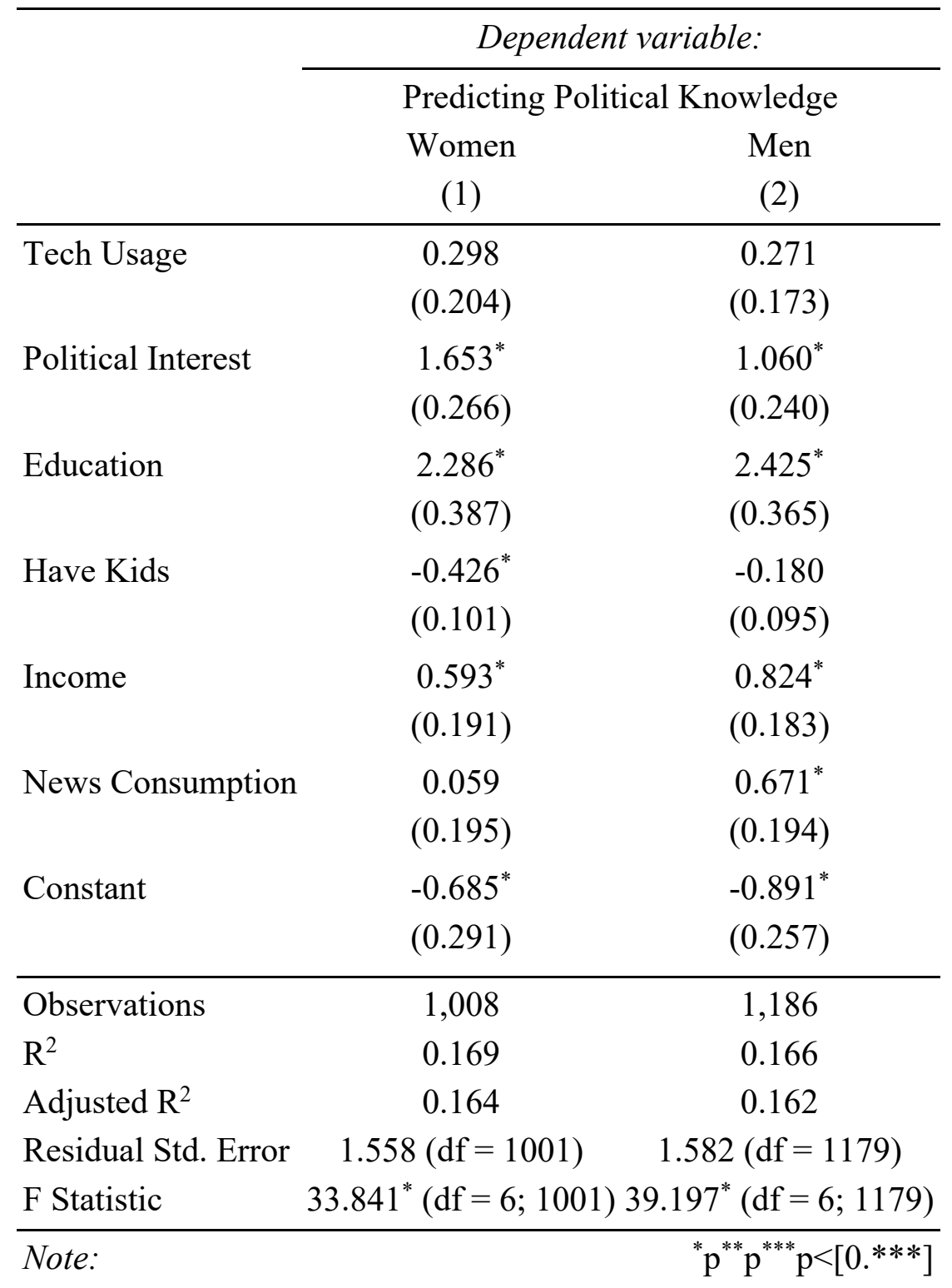


${ }^{i}$ Debate exists regarding the usefulness of typical political knowledge batteries, where the questions are often static in nature and relate to national-level politics (Barabas et al., 2014; Kuklinski \& Quirk, 2001; Lupia, 2016). Measures of political knowledge in this study come from the General Social Survey and American National Election Studies, which tend to rely on the more typical measures of political knowledge.

ii Our study relies on the political knowledge measures from the 2016 American National Election Study. These questions did not include "don't know" as an available response option.

iii The 2014 GSS sample had 2,538 total respondents, with 45\% indicating that they were male compared to $55 \%$ female. The ANES had a total of 4,271 respondents, the gender breakdown was $46.5 \%$ male, $52.3 \%$ female, and $1.2 \%$ who did not answer.

iv For each response, only those who responded correctly were coded as one, while those who did not give the correct response were coded as zero. For each of the five questions, there was a portion of the sample were not asked to complete the post-election interview or the ANES coded them as "no post data." For each of the five questions this was 14.5\% of the total sample. The differences in this omitted cases was less than 1\% between men and women and therefore should not bias the sample in any meaningful way.

${ }^{v}$ A full regression table is available in the Appendix

${ }^{\text {vi }}$ The effect size of usetech on political knowledge was .271 with 95\% CI $=[.224, .311]$ for the male sample. For the female sample the effect size of usetech was .297 with $95 \%$ CI $=[.250, .337]$ 